\title{
Improved subjective symptoms of conjunctivochalasis using bipolar diathermy method for conjunctival shrinkage
}

This article was published in the following Dove Press journal:

Clinical Ophthalmology

30 September 2011

Number of times this article has been viewed

\author{
Tomoyuki Kashima ${ }^{1,2}$ \\ Hideo Akiyama' \\ Fumihide Miura ${ }^{2}$ \\ Shoji Kishi' \\ 'Department of Ophthalmology, \\ Gunma University School of \\ Medicine, Gunma, Japan; ${ }^{2}$ Department \\ of Ophthalmology, Saku Central \\ Hospital, Nagano, Japan
}

Purpose: To evaluate the improvement in subjective symptoms of conjunctivochalasis after bipolar coagulation.

Methods: Forty-three eyes of 26 patients (average age, $75.7 \pm 8.4$ years) were included in this study. The inferior conjunctivas were cauterized between April 2009 and June 2010. Surgery involved pinching the excess conjunctiva and performing bipolar cauterization after subconjunctival injection of a local anesthetic agent. Patients were asked to describe the postoperative foreign-body sensation and change in subjective symptoms 1 month postoperatively, with the preoperative symptom score defined as 10 .

Results: Twenty-two patients $(84.6 \%)$ reported symptom relief immediately after the procedure, though all patients had a mild gritty sensation for 1-2 weeks postoperatively. The mean postoperative symptom score obtained from the questionnaire was $3.27 \pm 3.31$, which was significantly lower than the preoperative score $(P<0.0001)$. No patients had experienced recurrent symptoms at the end of the follow-up period.

Conclusion: Thermal cauterization can achieve conjunctival shrinkage and adherence to the subconjunctival tissues. Operation time is only a few minutes, postoperative pain is not severe, and the procedure can be performed in an outpatient clinic, all of which represent benefits to the patients.

Keywords: coagulation, cauterization, conjunctival injection

\section{Introduction}

Conjunctivochalasis (CCh) causes watery eyes, ocular irritation, and discomfort. ${ }^{1}$ Epiphora is mainly caused by obstruction of the lacrimal pathway; however, some patients suffer from epiphora without lacrimal pathway obstruction, and CCh may contribute to this condition in these patients. A histopathologic study showed fragmentation of the subconjunctival elastic fibers in patients with $\mathrm{CCh} .{ }^{2}$ Slack conjunctival tissue can lead to epiphora through mechanical blockage of the lacrimal puncta and tear meniscus formation. ${ }^{3-5}$ Moreover, the mechanical friction and negative pressure exerted on the tear meniscus by $\mathrm{CCh}$ also cause corneal and/or conjunctival abrasion, leading to ocular irritation and discomfort. Removal of the slack conjunctiva enables the formation of a clear single tear meniscus and eliminates the blocked puncta, which leads to improved epiphora. ${ }^{4}$ Although $\mathrm{CCh}$ is a common cause of ocular surface irritation and watery eyes, it is generally diagnosed as an unidentified complaint, and its clinical relevance is often overlooked. ${ }^{6}$

Various therapeutic procedures for $\mathrm{CCh}$ have been reported, including resection, suture fixation, fibrin glue, and coagulation. ${ }^{1,7,8}$ Resection is the most common treatment in Japan, ${ }^{1}$ but this procedure requires conjunctival stitches, which often generate severe
Correspondence: Tomoyuki Kashima Department of Ophthalmology, Gunma University School of Medicine, 3-39-I5 Showamachi, Maebashi, Gunma 37I-85I-I, Japan

Tel +8I 272208338

Fax +8I 53220384 I

Email kasimatomoyuki@yahoo.co.jp 
postoperative ocular irritation that may worsen several weeks postoperatively. However, the suturing and fibrin glue methods also have disadvantages. The long-term effects of the suture method have not been confirmed. The fibrin glue method with amniotic membrane transplantation is newer and able to omit the need for stitches, but is not widely performed because the amniotic tissue is not readily available. Haefliger et $\mathrm{al}^{9}$ reported the use of a coagulation method using bipolar forceps, but all patients had residual postoperative $\mathrm{CCh}$. Gumus et al ${ }^{10}$ also reported $\mathrm{CCh}$ areas were decreased significantly after conjunctival cauterization for $\mathrm{CCh}$ using anterior segment optical coherence tomography.

This paper reports a new surgical method for CCh using bipolar forceps. Changes in subjective postoperative symptoms were assessed using a questionnaire.

\section{Materials and methods}

A total of 43 consecutive eyes of 26 patients (18 women, 8 men; age range, 56-87 years; mean, $75.7 \pm 8.4$ ) were examined at the Department of Ophthalmology, Gunma University School of Medicine or Saku General Hospital, from April 2009 to June 2010. The inclusion criteria were (1) the presence of excess conjunctiva emerging above the edge of the lower eyelid, and (2) subjective symptoms such as epiphora, irritation, and discomfort which were not improved by topical medication, including artificial tears, hyaluronic acid and/or nonsteroidal anti-inflammatory drugs. The subjective preoperative symptoms are shown in Table 1. Eleven patients had epiphora, 12 had ocular irritation, and three had ocular discomfort. One surgeon (KT) performed all examinations and operations. Patients with lacrimal pathway occlusion, including obstruction of the lacrimal canaliculus and nasolacrimal duct, ectropion of the lacrimal puncta, horizontal eyelid laxity, and eyelash/globe contact were excluded. All research and interviews complied with the guidelines of the Declaration of Helsinki. All patients provided informed consent. The postoperative follow-up periods ranged from 59 to 465 days (average, $220.5 \pm 111.2$ ).

The originally developed technique of bipolar coagulation using the tuck and coagulation method to shrink excessive conjunctiva is described below (Figure 1). ${ }^{1}$ After application of topical anesthetics of oxybuprocaine hydrochloride, $0.2 \mathrm{~mL}$ of $1 \%$ lidocaine with epinephrine was injected into the space between the conjunctiva and Tenon's capsule. Intraoperatively, the patients were instructed to look upward. The excess conjunctiva was grasped $4 \mathrm{~mm}$ from the limbus and coagulated, starting with low voltage (power level 0.6) bipolar cauterization (TB50, B Braun Aesculap, Japan) and
Table I Patient symptoms

\begin{tabular}{|c|c|c|c|}
\hline Case & $\begin{array}{l}\text { Subjective } \\
\text { symptoms }\end{array}$ & $\begin{array}{l}\text { Preoperative } \\
\text { symptom scale }\end{array}$ & $\begin{array}{l}\text { Postoperative } \\
\text { symptom scale }\end{array}$ \\
\hline $\mathrm{I}$ & FBS & 10 & 0 \\
\hline 2 & WE & 10 & 2 \\
\hline 3 & WE & 10 & 2 \\
\hline 4 & WE & 10 & 0 \\
\hline 5 & $\mathrm{D}$ & 10 & 5 \\
\hline 6 & WE & 10 & 2 \\
\hline 7 & FBS & 10 & 3 \\
\hline 8 & FBS & 10 & 1 \\
\hline 9 & WE & 10 & 10 \\
\hline 10 & WE & 10 & 0 \\
\hline 11 & FBS & 10 & 0 \\
\hline 12 & $D$ & 10 & 10 \\
\hline 13 & FBS & 10 & 1 \\
\hline 14 & WE & 10 & 5 \\
\hline 15 & WE & 10 & 10 \\
\hline 16 & FBS & 10 & 2 \\
\hline 17 & FBS & 10 & 1 \\
\hline 18 & WE & 10 & 5 \\
\hline 19 & FBS & 10 & 5 \\
\hline 20 & WE & 10 & 1 \\
\hline 21 & FBS & 10 & 10 \\
\hline 22 & WE & 10 & 5 \\
\hline 23 & FBS & 10 & 2 \\
\hline 24 & $\mathrm{D}$ & 10 & 2 \\
\hline 25 & FBS & 10 & 0 \\
\hline 26 & FBS & 10 & 1 \\
\hline Average & & 10 & 3.269231 \\
\hline SD & & & 3.311492 \\
\hline
\end{tabular}

Abbreviations: FBS, foreign-body sensation; WE, watery eyes; D, discomfort; $\mathrm{SD}$, standard deviation.

gradually increasing the voltage until the conjunctiva was coagulated. Coagulation was considered to be adequate when the conjunctiva turned white. Coagulation was performed at 5-10 sites in an arc on the inferior bulbar conjunctiva (Figure 2). The slack conjunctiva shrank and tightened immediately after coagulation. The procedure only took a few minutes to complete for each eye (see Supplementary video "CCh coagulation movie.mpg," which demonstrates this procedure). Postoperative betamethasone phosphate ophthalmic ointment was administered to prevent acute chemosis, and levofloxacin ophthalmic solution and betamethasone phosphate ophthalmic solution were prescribed to be taken six times daily. One week postoperatively, fluorometholone four times daily was substituted for these drops. All drugs were stopped 1 week later. Patients were asked to remember the severity of the subjective symptoms preoperatively. They were then asked to rate their symptoms 1 month postoperatively on the basis of "If the greatest severity of preoperative symptoms was 10 , on a scale of 1 to 10 , how great are the present symptoms? (better or worse?)", and 


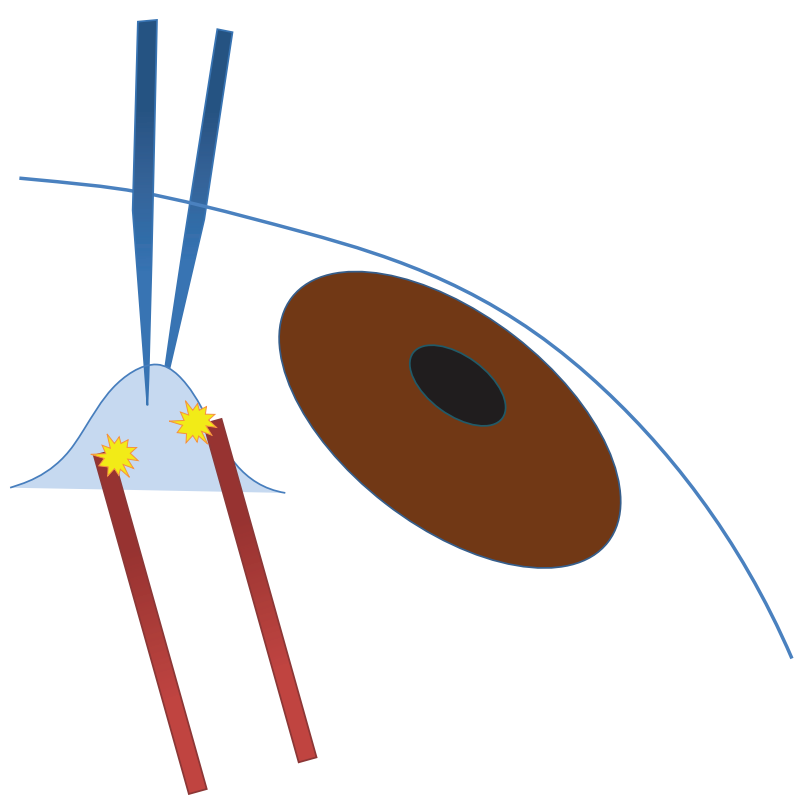

Figure I Schema of conjunctival coagulation. The operator instructs the patient to gaze upward and picks up the conjunctiva using hook forceps (red). The tissue was coagulated using coagulation forceps (blue) and minimal electrical power. Yellow bursts indicate coagulation.

Notes: Adapted with permission from Kashima T, Miura F, Akiyama H, Kishi S. Simple surgery for conjunctivochalasis using shrinking effect of heat coagulation with biopolar coagulation forceps. Atarashii Ganka 2010;27:229-233. ${ }^{18}$

"Was the irritation in the immediate postoperative period mild, moderate, or severe?".

Statistical analyses were performed using MannWhitney's $U$ test. Values of $P<0.05$ indicated statistical significance. All statistical analyses were carried out using SPSS for Windows (SPSS Japan Inc, Tokyo, Japan).

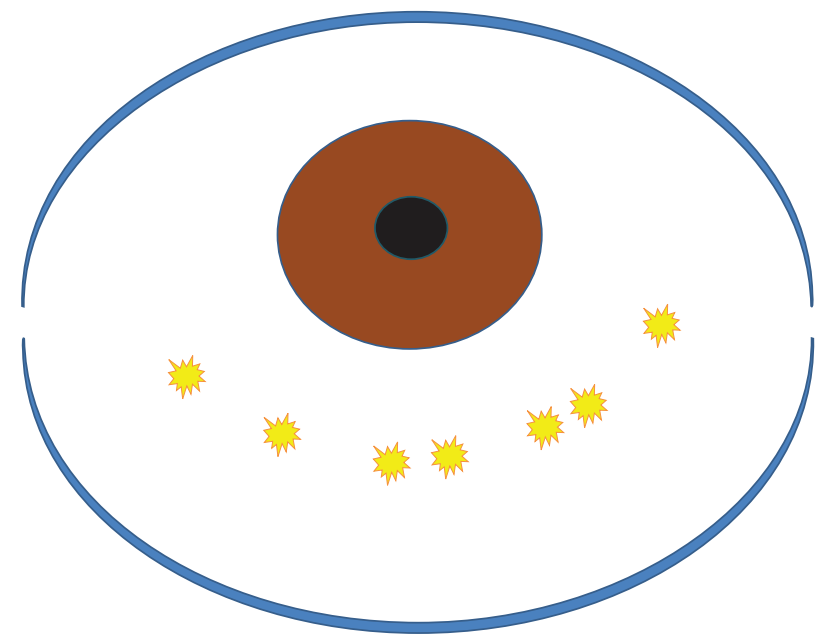

Figure 2 Schema of the coagulation area. The surgical area is in the inferior conjunctiva, $4 \mathrm{~mm}$ below the corneal limbus. The inferonasal and inferotemporal areas, which are hidden by the lower eyelid, should also be treated. Five to ten pulsatile coagulations are applied to the inferior conjunctiva (yellow bursts).

Notes: Adapted with permission from Kashima T, Miura F, Akiyama H, Kishi S. Simple surgery for conjunctivochalasis using shrinking effect of heat coagulation with biopolar coagulation forceps. Atarashii Ganka 2010;27:229-233. ${ }^{18}$

\section{Results}

All patients reported only mild postoperative irritation. A total of 24 patients had conjunctival injection that resolved within 2 weeks, though this was prolonged for 1 month in two patients with severe dry eye. The coagulated region was stained with fluorescein 1 week postoperatively in all patients. The subjective symptoms resolved along with diminution of the staining. The coagulated conjunctiva adhered to the sclera or Tenon's capsule within 1 month (Figures 3-5), and the integrity of the tear meniscus was restored in all but two patients. These two patients had severe $\mathrm{CCh}$ with drooping lower eyelids, and residual postoperative $\mathrm{CCh}$. No severe side effects such as symblepharon or restriction of ocular motility developed. The subjective symptoms clearly decreased, but a second surgery was performed to further improve the outcome in one patient. A normal tear meniscus was obtained after the second procedure. No recurrent $\mathrm{CCh}$ developed postoperatively in any patient during the observation period.

The mean postoperative symptom score was $3.27 \pm 3.31$, which was significantly lower than the preoperative symptom score $(P<0.0001)$. The preoperative symptoms improved in 22 cases $(84.6 \%)$, but not in the other four cases $(15.4 \%)$. Two patients with no improvements in subjective symptoms had watery eyes, one patient had ocular irritation, and one patient had discomfort. There was no correlation between the type of subjective symptoms and the postoperative scores. No patient complained of worsened subjective symptoms.

\section{Discussion}

Patients with CCh were treated using the coagulation method involving bipolar coagulation. The operation was performed rapidly in a clinic setting, and no patients experienced intolerable postoperative ocular irritation. The goal of surgery to treat $\mathrm{CCh}$ is to remove and anchor the slack conjunctiva. ${ }^{11}$ The authors of this present paper have previously performed conventional resection, but this does not eliminate severe postoperative irritation caused by the residual knots and persistent small lacerations in the sutured wound. The coagulation method ${ }^{9,10}$ achieves conjunctival shortening by electrical coagulation, which also promotes fixation of the conjunctiva to the sclera or Tenon's capsule. Although the authors of this present paper were unable to confirm tissue adhesion, no eyes showed overflow of the conjunctival tissue at the inferior edge of the eye postoperatively. Because the excess conjunctiva may be functionless, the method did not restrict ocular movement. The short surgical time was a further advantage of this method; surgery was completed in about 5 minutes per eye. The ease of 

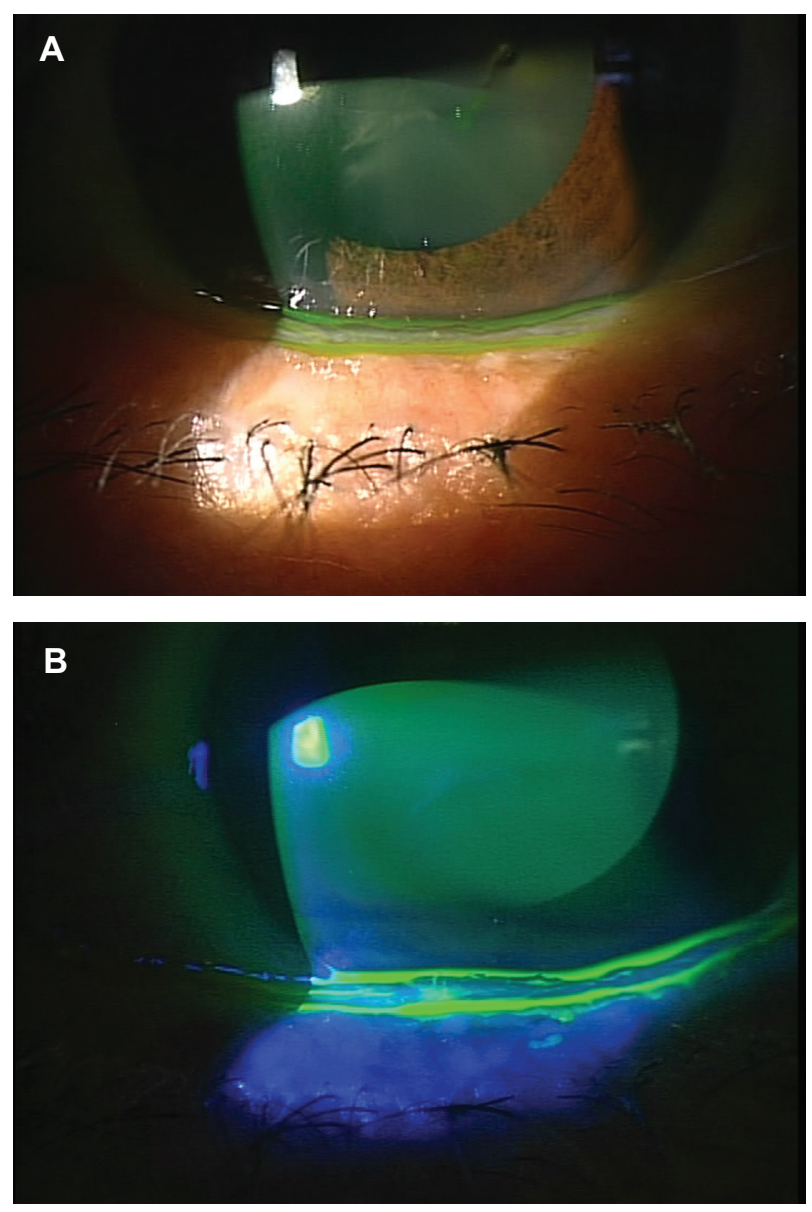

Figure 3 The patient presented with ocular irritation. (A) Preoperative photograph showing CCh on the edge of the lower eyelid. The patient also had keratoconjunctivitis sicca. (B) A preoperative photograph showing fluorescein staining. The CCh divides the tear meniscus into two layers. Punctate conjunctivitis is seen on the CCh.

Abbreviation: $\mathrm{CCh}$, conjunctivochalasis.

performance and lack of requirement for special instruments means that this procedure represents an easily accessible treatment for both patients and medical staff at the outpatient clinic. Because no sutures are placed in the conjunctiva, most patients experienced no postoperative discomfort.

The surgical benefit of the coagulation method can be measured on the basis of the difference between preoperative and postoperative subjective symptom scores. Although the National Eye Institute Visual Function Questionnaire is the major instrument used to investigate visual function, ${ }^{12-14}$ it is unsuitable for evaluating the discomfort associated with $\mathrm{CCh}$. In the current study, the questionnaire was adapted to measure the subjective symptoms of CCh. Because of the unknown extent of postoperative change, a nonsliding scale was used to assess the subjective symptoms.

$\mathrm{CCh}$ is often diagnosed as an unidentified complaint in elderly patients. Because the symptoms of $\mathrm{CCh}$ are not
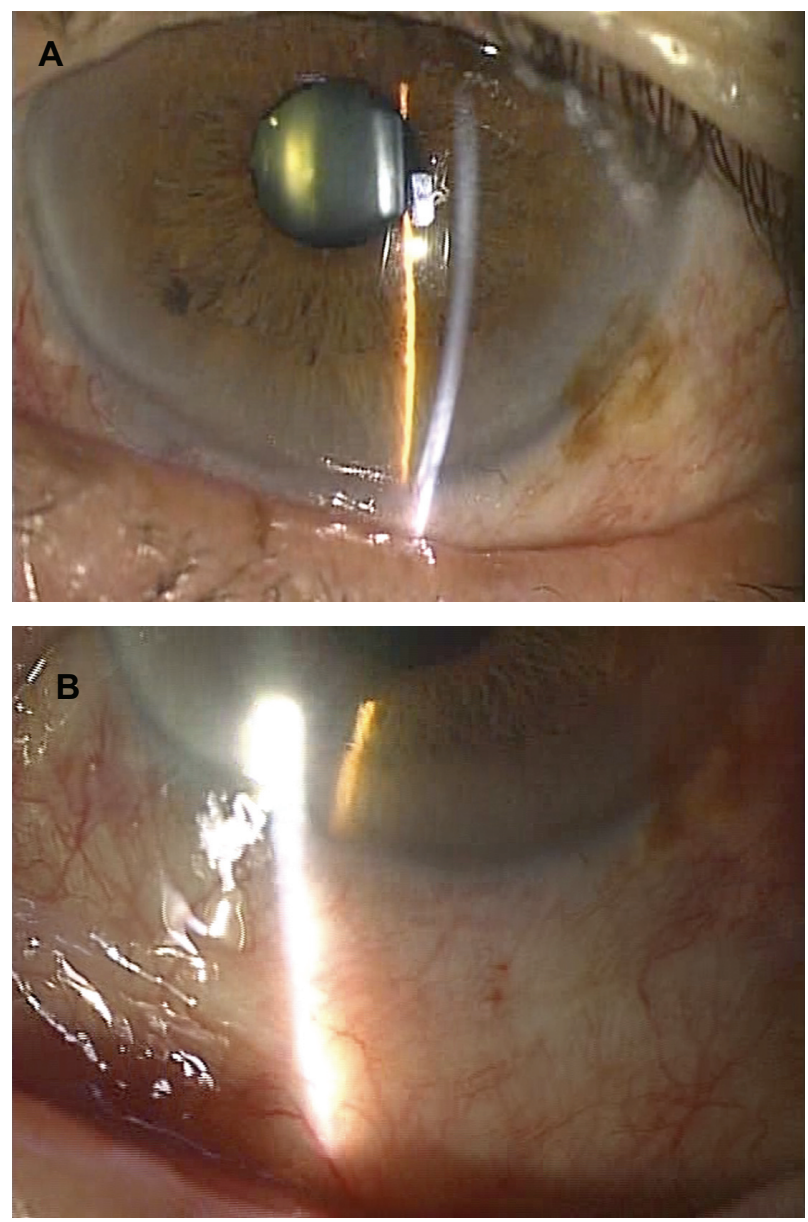

Figure 4 Photograph I month postoperatively. (A) The conjunctivochalasis has resolved, but slight conjunctival injection remains. (B) A white scar has formed in the coagulated region and is accompanied by mild injection. Conjunctival injection tends to be prolonged in patients with keratoconjunctivitis sicca.

severe, its treatment should not be a burden for patients. Resection of the conjunctiva sometimes leads to postoperative foreign-body sensation and ocular pain. However, no patients reported severe postoperative irritation or pain after use of the current method.

A second operation was needed in one patient with severe $\mathrm{CCh}$, but because the procedure is not painful, a second procedure is generally considered to be acceptable. Patients should be advised preoperatively of the advantages (short surgical time, mild postoperative irritation) and potential disadvantage (repetition of surgery) of this method.

Although Haefliger et al ${ }^{10}$ previously reported a coagulation method for CCh using bipolar forceps, residual postoperative $\mathrm{CCh}$ was present in all their patients. Because the slack conjunctiva was not grasped with forceps, their method only coagulated the conjunctival surface, resulting in only slight shrinkage and fixation of the conjunctival 

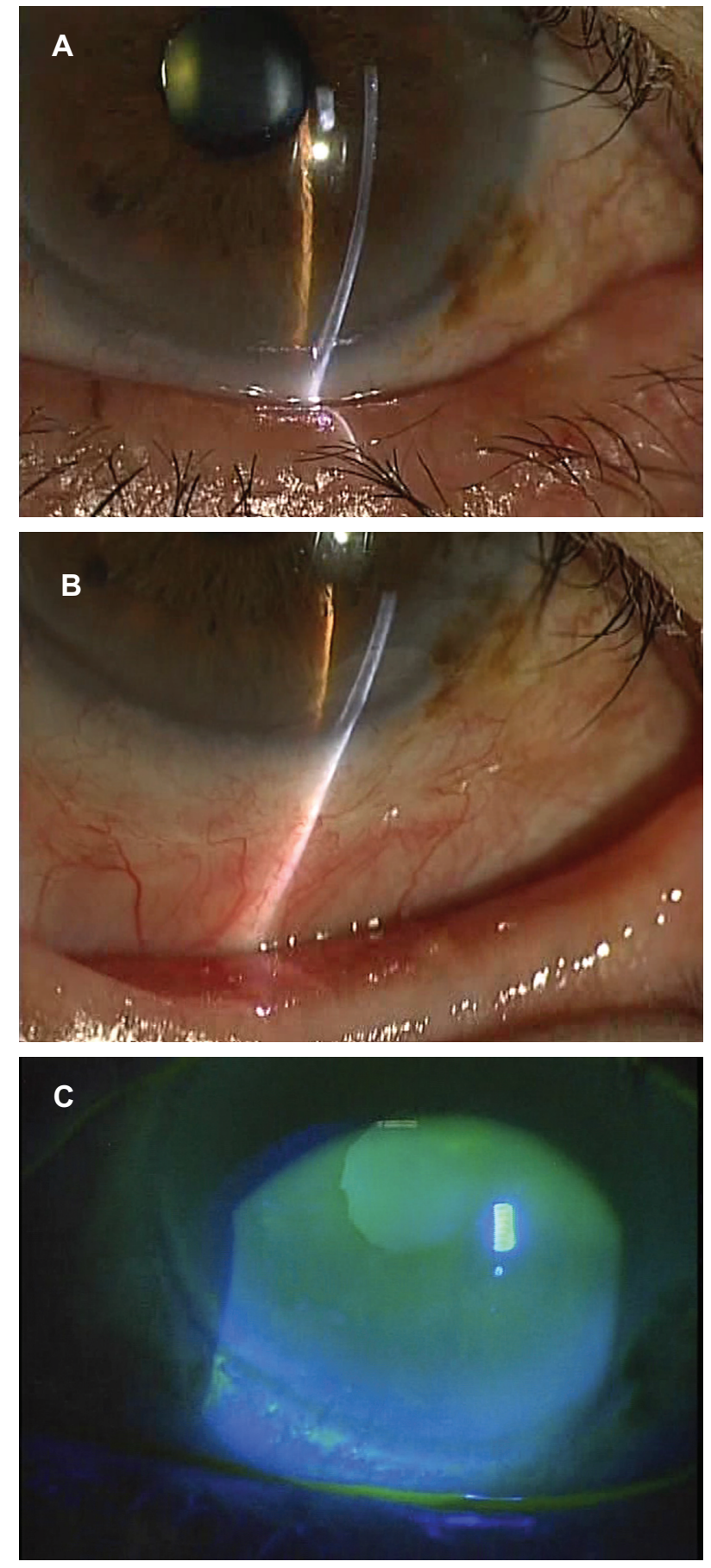

Figure 5 Photograph 3 months postoperatively. (A) The conjunctivochalasis has resolved. Ocular irritation has decreased to $10 \%$ of the preoperative level. (B) White scar tissue has formed in the area of coagulation, but is inconspicuous (C) Photograph obtained 3 months postoperatively showing fluorescein staining. The single tear meniscus is restored and the watery eye has resolved.

tissue. The coagulation method used in this current study has improved on this by grasping a large amount of slack conjunctival tissue, making it possible to treat sufficient tissue and cause scar formation in the deeper subconjunctival tissue. This coagulation method appears to produce better outcomes than the method of Haefliger et al. ${ }^{9}$
The coagulation method caused only mild postoperative irritation or pain, and the coagulated area did not form any tissue defects visible by biomicroscopy. The coagulated region was covered by white, slightly elevated tissue that could be stained by fluorescein, and which resolved within 1 week postoperatively. The authors speculated that this white tissue was a remnant of the necrotic tissue resulting from coagulation, and that the postoperative irritation was reduced because this tissue covered the coagulated area, in contrast with the resection method, which denudes the epithelial surface and exposes nerve endings.

There was no recurrence of $\mathrm{CCh}$ during the observation period, but the long-term prognosis is unknown. Conjunctival injuries need about 3 weeks to heal, and tissue remodeling takes about $2-3$ months. ${ }^{15-17}$ The observation period in the current study was sufficiently long to predict that the long-term recurrence rate was likely to be low.

In conclusion, the coagulation method for treating $\mathrm{CCh}$, involving bipolar coagulation with conjunctival pinching, had a high success rate, a short surgical time and short recovery time, and represented a minimal treatment burden for patients. Patients with CCh not associated with other complaints should thus undergo coagulation treatment prior to the consideration of other treatment methods.

\section{Disclosure}

The authors report no conflicts of interest in this work.

\section{References}

1. Yokoi N, Inatomi T, Kinoshita S. Surgery of the conjunctiva. Dev Ophthalmol. 2008;41:138-158.

2. Watanabe A, Yokoi N, Kinoshita S, Hino Y, Tsuchihashi Y. Clinicopathologic study of conjunctivochalasis. Cornea. 2004;23:294-298.

3. Liu D. Conjunctivochalasis. A cause of tearing and its management. Ophthal Plast Reconstr Surg. 1986;2:25-28.

4. Serrano F, Mora LM. Conjunctivochalasis: a surgical technique. Ophthalmic Surg. 1989;20:883-884.

5. Meller D, Tseng SC. Conjunctivochalasis: literature review and possible pathophysiology. Surv Ophthalmol. 1998;43:225-232.

6. Kheirkhah A, Casas V, Blanco G, et al. Amniotic membrane transplantation with fibrin glue for conjunctivochalasis. Am J Ophthalmol. 2007; 144:311-313.

7. Otaka I, Kyu N. A new surgical technique for management of conjunctivochalasis. Am J Ophthalmol. 2000;129:385-387.

8. Nagai M, Hatou S, Ohno K, Mochizuki H, Yamada M. Surgical repair of conjunctivochalasis with anchoring sutures. Atarashii Ganka. 2008;25:1557-1560.

9. Haefliger IO, Vysniauskiene I, Figueiredo AR, Piffaretti JM. Superficial conjunctiva cauterization to reduce moderate conjunctivochalasis. Klin Monatsbl Augenheilkd. 2007;224:237-239.

10. Gumus K, Crockett CH, Pflugfelder SC. Anterior segment optical coherence tomography: a diagnostic instrument for conjunctivochalasis. Am J Ophthalmol. 2010;150:798-806.

11. Kheirkhah A, Casas V, Esquenazi S, et al. New surgical approach for superior conjunctivochalasis. Cornea. 2007;26:685-691. 
12. Suzukamo Y, Oshika T, Yuzawa M, et al. Psychometric properties of the 25-item National Eye Institute Visual Function Questionnaire (NEI VFQ-25), Japanese version. Health Qual Life Outcomes. 2005;3:65.

13. Mangione CM, Lee PP, Pitts J, et al. Psychometric properties of the National Eye Institute Visual Function Questionnaire (NEI-VFQ). NEI-VFQ Field Test Investigators. Arch Ophthalmol. 1998;116: 1496-1504.

14. Balcer LJ, Baier ML, Kunkle AM, et al. Self-reported visual dysfunction in multiple sclerosis: results from the 25-Item National Eye Institute Visual Function Questionnaire (VFQ-25). Mult Scler. 2000;6:382-385.

15. Geggel HS, Friend J, Thoft RA. Conjunctival epithelial wound healing. Invest Ophthalmol Vis Sci. 1984;25:860-863.
16. Chou H, Shimizu T, Endo Y, Tani T. Wound healing. Surgery Frontier. 2007;14:56-61.

17. Matsuura N, Okita K, Umemoto M, Yamamoto S. Cellular and molecular mechanisms of wound healing. Surgery Frontier. 2003;10:121-126.

18. Kashima T, Miura F, Akiyama H, Kishi S. Simple surgery for conjunctivochalasis using shrinking effect of heat coagulation with biopolar coagulation forceps. Atarashii Ganka 2010;27:229-233.

\section{Supplementary video}

"CCh coagulation movie.mpg"

The video shows the procedure of the method used in this study.
Clinical Ophthalmology

\section{Publish your work in this journal}

Clinical Ophthalmology is an international, peer-reviewed journal covering all subspecialties within ophthalmology. Key topics include: Optometry; Visual science; Pharmacology and drug therapy in eye diseases; Basic Sciences; Primary and Secondary eye care; Patient Safety and Quality of Care Improvements. This journal is indexed on

\footnotetext{
Submit your manuscript here: http://www.dovepress.com/clinical-ophthalmology-journal
}

\section{Dovepress}

PubMed Central and CAS, and is the official journal of The Society of Clinical Ophthalmology (SCO). The manuscript management system is completely online and includes a very quick and fair peer-review system, which is all easy to use. Visit http://www.dovepress.com/ testimonials.php to read real quotes from published authors. 